\title{
Cost-Utility Analysis of Malaysian Elderlies Living in Public Long-Term Care Institutions
}

\author{
Syazreen Niza Shair ${ }^{1 *}$ and Thomas Sachi Purcal ${ }^{2}$ \\ ${ }^{1}$ Centre for Actuarial Science, Faculty of Computer and Mathematical Sciences, Universiti Teknologi MARA, \\ 40500 UiTM, Shah Alam, Selangor, Malaysia \\ ${ }^{2}$ Centre for Risk Analytics, Department of Actuarial Studies and Business Analytics, Macquarie Business \\ School, Macquarie University, North Ryde, NSW 2109, Sydney, Australia
}

\begin{abstract}
This research compares the quality of life of Malaysian elderlies living in public formal long-term care institutions, including residential care and nursing home care. It provides evidence of the cost-effectiveness of both programs. The sample of Malaysian elderlies aged 60 years and above was collected from the World Health Survey, including five dimensions of health status: mobility, self-care, usual activities, pain and discomfort, and anxiety and depression. Each of the dimensions has three levels, including 1 ("no problems"), 2 ("some problems") and 3 ("major problem"). The quality-adjusted life-years (QALYs) of elderlies living in both institutions are estimated using a generic health-related measurement method, EQ-5D. In addition, cost-utility analysis is adopted to compare the effectiveness of programs in allocating resources. The QALY of those living in nursing home care is reasonably lower than those in residential care due to their worse chronic health conditions. The majority are categorised as severely disabled. The cost-effectiveness evaluation of each public long-term care model suggests that the residential care program is cost-effective, with the cost per QALY being MYR22 945. At the same time, a nursing home for disabled people is not effective as the cost per QALY is MYR57 822, falls outside the willingness to pay (WTP) range between (MYR 19,929-MYR 28,470).
\end{abstract}

ARTICLE INFO

Article history:

Received: 08 July 021

Accepted: 10 September 2021

Published: 03 December 2021

DOI: https://doi.org/10.47836/pjssh.29.4.16

$\overline{\text { E-mail addresses: }}$

syazreen@uitm.edu.my (Syazreen Niza Shair)

sachi.purcal@mq.edu.au (Thomas Sachi Purcal)

* Corresponding author
Keywords: Cost-utility analysis, EQ5D, long term care, population ageing, quality-adjusted-life-years

\section{INTRODUCTION}

As the Malaysian population ages, issues surrounding long-term care, particularly institutional or nursing home care, are coming more into focus (Mohd Tobi et a1., 2017). These issues have yet to be 
recognised in policy, which encourages children or family members to provide informal caregiving to elderly parents. Although family members have long practised informal care, this tradition weakens over time due to a falling number of children, urbanisation, and higher labour force participation among women (Mafauzy, 2000). Commentators suggest there is a degree of urgency for policy change or reform from informal care to formal institutional care (Ambigga et al., 2011; Forsyth \& Chia, 2009; Goh \& Lai, 2013; Li \& Khan, 2012).

A comprehensive assessment of elderlies' quality of life living in long-term care institutions is essential to understand the ageing process in different residential settings that may impact elderlies' wellness and eventually provide evidence to support care programs implemented by the government. For example, a study conducted in Brazil reported that the quality of life (QoL) of older persons living in longterm care facilities is lower than those living in the community because they were older and experienced worse socioeconomic and health conditions (Vitorino et al., 2013). Similarly, Kiik and Nuwa (2020) research indicated that Indonesian elderlies living in community-dwelling experience higher QoL than those residing in welfare institutions. Moreover, Su and Wang (2019) found that elderlies residing in community-based home care in Guangzhou city generally showed better QoL than institutional care. These findings suggest that the support from the community is significant and leads to a greater sense of belonging, and positively influences the wellness of elderlies.

In contrast, a study conducted in rural India showed that the QoL of elderlies from nursing homes is higher with better physical health than those elderlies in the community due to regular, timely food intake and less physical activity exertion (Kumar et al., 2016). Nevertheless, no research has been done thus far that estimates the QoL of elderlies living in the community or formal institutional long-term care, particularly those offered by the Malaysian government. This information is necessary to evaluate how effective the modes of institutional long-term care are in Malaysia.

Malaysia's public long-term care program is a safety net program that provides welfare for destitute older people. These public programs include both formal and informal care. The formal care programs included residential homes (Rumah Sri Kenangan) and nursing homes (Rumah Ehsan). Residents of these formal care homes are elderlies aged 60 and above, who do not have family members or caregivers to provide care. While residential homes accept only independent enough to take care of themselves, nursing homes provide care intensively around the clock to more severely disabled older adults. For informal care, monthly cash payments are given to caregivers or family members of the poor and disabled elderly. In addition, day-care centres are available within the community to provide temporary care services for elderly parents while their children are at work ("Warga Emas", 2021). 
Up until today, there has been no formal funding for Malaysian long-term care. Nevertheless, the costs of receiving care from these public institutions are fully subsidised by the government. This study focuses on formal care as the costs of these institutional long-term care are expensive given that the long-term care costs are not only related to professional care for disabled elderly who are in need care and could not perform their daily activities but also comprised the costs for doctor visits, medical expenses, beds, and other facilities. Due to the high costs incurred for these programs, estimating how effectively the government allocated resources is crucial. Inadequate management of long-term care programs is likely to result in poor quality of life among elderlies (Nikmat et al., 2011). It imposes a substantial economic burden on the government in the form of increased long-term care costs.

The most common program effectiveness evaluation method is cost-effectiveness analysis (CEA) which compares standard care with alternative care costs and effects (Drummond et al., 2005). Results are not expressed in monetary terms as in costbenefit analysis (CBA), but forms such as life-years gained. Cost-utility analysis (CUA) is another approach that measures the benefits gained in terms of improved health or quality of life. As such, it is a narrower approach than CEA. CUA results are typically expressed in costs per qualityadjusted life-year (QALY) gained by taking one program instead of another. Alternatively, the costs per QALY of one program can be compared with societal willingness to pay (WTP) for healthcare interventions. One program or intervention is considered effective if the cost for a QALY falls within the WTP range (Shafie et al., 2014).

According to Makai (2014), QALYs are arrived at by adjusting the length of time affected by the health outcome with a health-related quality of life (HRQoL) or health utility index, ranging from 0 to 1 . This HRQoL index can be measured using a generic measuring preference instrument based on individuals' health attributes, such as EQ-5D. Bulamu et al. (2015) suggest that the EQ-5D is the most applied generic instrument in community and residential care among older adults. The EQ-5D instrument is available for many countries, including Yusof et al. (2012) have developed the EQ-5D value set for Malaysia. Thus, this paper will adopt the EQ-5D instrument to measure the HRQoL index of the Malaysian elderly and eventually estimate the CUA of public residential care and nursing home care.

According to Dahlan et al. (2010), older adults living in institutions experience adverse effects on health and well-being as the institutional environment creates dependency and offers less privacy. This paper will use a generic health-related measurement method, EQ-5D, to measure the quality-adjusted life years (QALYs) of the Malaysian elderly living in both institutions: residential homes and nursing homes. Although the transition of elderlies receiving care from residential dwellings 
to the nursing home is often a function of the disability stage, there is currently no evidence showing that living in residential homes provides a higher quality of life than nursing homes. In addition to QALYs, we measure the cost-utility analysis as it is essential to identify how efficient current programs are in improving the quality of life of the elderly.

\section{MATERIALS AND METHODS}

Next, we describe data used to perform the economic evaluation of public long-term care programs. This paper adopts cost-utility analysis, which measures costs per QALY. The cost data were obtained from the budget announced by the Minister of Women, Family and Community, Datuk Heng Kai See, in 2012, that the government spent MYR 26.79 million for public residential care and MYR 5.8 million for public nursing home care in a year (Bernama, 2012).

In addition, to calculate QALY, we use the World Health Survey (WHS, 2012) survey, which was carried out in many countries, including Malaysia. The sample for Malaysia consists of 6,037 people over the age of 18 , of which 796 of them were elderly aged 60 and above. This research includes only those aged 60 years and above to reflect the minimum entry age to public long-term care institutions. There are nine main sections in the survey. However, we gather specific data from the Section 2 to be consistent with the EQ-5D instrument, referring to the individual's health state description. Data were extracted using the $R$ program.

\section{The EQ-5D Instrument}

The EQ-5D is a generic measurement of health status that is widely used as a key component for cost-utility analysis. The EQ5D was originally developed in Europe by The EuroQol Group (1990) and published the updated recently (EuroQol, 2019). The EQ-5D instrument includes five dimensions of health assessment which are: i. mobility, ii. self-care, iii. usual activities, iv. pain and discomfort and v. anxiety and depression. This study used the WHS (2012) survey and chose the respective survey questions that represent the five dimensions of EQ-5D as below:

- 2010: "Overall in the last 30 days, how much difficulty did you have with moving around?" (First dimension: mobility),

- q2020: "Overall in the last 30 days, how much difficulty did you have with self-care, such as washing or dressing yourself?" (Second dimension: self-care),

- q2060: “Overall in the last 30 days, how much difficulty did you have with personal relationship or participation in the community?" (Third dimension: usual activities),

- q2030: "Overall in the last 30 days, how much bodily aches or pains did you have?" (Fourth dimension: pain and discomfort),

- q2090: “Overall in the last 30 days, how much of a problem did you have with feeling sad, low or depressed?" (Fifth dimension: anxiety and depression). 
Each of the five dimensions has three levels, including 1 ("no problems"), 2 ("some problems") and 3 ("major problem"). Each of 796 Malaysian elderlies answered the five chosen questions combined to get an individual's EQ-5D health state. The three levels in each of the five dimensions yield $3^{5}=243$ possible health states, identified by a five-digit code. For example, the EQ-5D state 21111 would represent an individual having some problems with mobility and no problem with self-care, usual activities, pain, and depression. A person with state 21111 is experiencing worse health than a person with state 11111 because the first has some problem with his mobility, whereas the second is in perfect health. Nonetheless, it is sometimes difficult to evaluate the health status between two different states. For instance, it is hard to say that 21111 state is better than 12111 , or vice-versa because the latter has some difficulties in self-care instead of mobility. Therefore, an index is required to represent the overall level of health of an individual.

The five-dimensional health states can be summarised and represented by a single summary number or an index value, which reflects how good or bad a health state is according to the preferences of the general population of a country. This index value is referred to as the healthrelated quality of life (HRQoL) or health utility score, obtained from the elicitation of the EQ-5D health states. The EQ-5D elicitation procedure has been undertaken by many countries worldwide. Most EQ-5D elicitation value sets have been obtained from a standardised valuation exercise, in which a representative sample of the general population in a country (EuroQol, 2019). This protocol is based on the time trade-off (TTO) valuation technique. Three methods are frequently used for eliciting the index from the EQ-5D five-digit health state, namely a visual analogue scale (VAS), a standard gamble (SG) or time trade-off (TTO). We chose the EQ-5D value set elicited using the TTO approach, as Yusof et al. (2012). The TTO elicitation equation developed by Yusof et al. (2012) was based on a Malaysian sample and is defined in Equation 1:

$H R Q o L=0.863-0.039$ (Mobility

Level 2) - 0.08(Mobility

Level3) - 0.061(Selfcare Level

2) - 0.083(Selfcare Level 3) -

0.03(Usual activites Level 3) - 0.09

(Pain Level 2) - 0.14(Pain Level

3) - 0.051(Depression Level 2) -

0.043(Depression Level 3) - 0.13N3

The regression equation above was estimated using levels 2 and 3 in each of the EQ-5D dimensions as a dummy variable, taking the value of one if they exist and 0 otherwise. The $N 3$ variable takes the value 1 if the health state consists of level 3 in any dimension. For example, if the health state of an elderly is 11213 , this would translate to $0.083-0.03-0.043-0.13=0.66$. This HRQoL index value ranges from 0 (the 
worst health status) to 1 (the best health status).

We did not directly conduct an EQ-5D survey to obtain the five-digit health state of the elderly living in public institutional long-term care as this would involve a large survey study. Instead, we employed the WHS (2012) survey data, choosing questions relevant to the EQ-5D and assuming these responses were representative of those residing in the government-sponsored long term care facilities. We subdivided the elderlies into two groupings and calculated each of the elderly's HRQoL. In the mobility question, the elderlies who responded to "major problem" (Level 3) are assumed to have some chronic condition and difficulties moving around. They are categorised as dependent elderlies and are likely to need care in a nursing home that provides care round the clock. Based on the samples, thirty elderlies fell under this severe category. This assumption meets the admissions criteria of the public nursing home (Rumah Ehsan), which cannot take care of oneself. The remaining elderlies are considered independent as they responded to "no problem" or "minor problem" (level 1 or level 2) in the mobility question. These independent elderlies represent those living in residential care because they meet the residential care (Rumah Sri Kenanga) admission criteria, which can take care of themselves. The HRQoL index values will facilitate the calculation of quality-adjusted life-years (QALYs) used to inform economic evaluations of healthcare interventions.

\section{Cost-Utility Analysis}

The cost-effectiveness evaluations of the two different types of institutional care are performed to identify the effectiveness of the programs in improving the quality of life of residents. We use a cost-utility analysis (CUA) approach to achieve this objective as follows:

$$
C U A=\frac{\text { Costs }}{Q A L Y}
$$

where Costs is the average yearly government expenditure for a stay in either residential care or nursing home care. The government fully funds these public longterm care institutions with the average annual costs of the programs, including beds, medicines, food, the activity of daily living assistance, and much more. The denominator of the formula, QALY represents the average quality-adjusted life-year, a preference-based health measure comprising both length and health-related quality of life (HRQoL). Specifically, QALY, is defined as

$$
\begin{aligned}
& \text { QALY = Life time spent in } \\
& \text { current health status } \times \text { HRQoL }
\end{aligned}
$$

Since the QALY's of the elderly living in the institutions is measured during their stay in a year, the Life time spent in current health status for each individual $i$ is set to one year, reducing the formula of QALY to just the HRQoL. The QALY is an index, a single number representing the overall level 
of an individual's health. This index ranges from 0 (the worst health status) to 1 (perfect health status). Therefore, we estimate the average value of HRQoL from the two groupings represents the mean score of the EQ-5D, the QALY for the groupings.

\section{RESULTS AND DISCUSSIONS}

As a result of population ageing, the costs of Malaysian public long-term care are projected to increase in the future. Hence, it is important to measure how effective these programs are. Shiroiwa et al. (2013) suggested that costs per QALY are a good measurement for cost-effectiveness in an economic evaluation. Therefore, we used the same measurement to examine the cost effectiveness of the Malaysian public residential care and nursing home programs.

The Malaysian public long-term care is a fully-funded government program consisting of residential care and nursing home care. Residential care provides care and services only for those elderly who are independent and require low levels of care. In contrast, nursing home care is for the severely disabled and dependent on professional care most of the time.

The percentage of the elderly population entitled to the Malaysian public longterm care programs was tiny. The report from the Operational Assistant Director of Social Welfare Department in 2012 indicated 2,084 older adults were living in public institutions in total which 1,847 of them were living in residential care and 237 were living in nursing home care. Of the 2,084 elderlies, 1,247 were males, and the remaining 837 were females ("Dimana silapnya", 2012). Out of these recipients, approximately $60 \%$ were males, and $40 \%$ were females. As calculated in Table 1, these reported numbers have resulted in a small percentage of coverage for Malaysia's public institutional care programs, $0.082 \%$ of the aged for residential care and $0.010 \%$ for nursing home care.

Table 1

The percentage of elderly living in public residential care and nursing home care in year 2012

\begin{tabular}{lcc}
\hline & $\begin{array}{c}\text { Residential } \\
\text { care }\end{array}$ & $\begin{array}{c}\text { Nursing } \\
\text { home }\end{array}$ \\
\hline $\begin{array}{l}\text { Number of elderlies } \\
\text { living in institutions }\end{array}$ & 1,847 & 237 \\
$\begin{array}{l}\text { Malaysian total elderly } \\
\text { estimates from DoSM }\end{array}$ & $2,262,800$ & $2,262,800$ \\
$\begin{array}{l}\text { Percentage of coverage } \\
\text { under the institutions } \\
(\%)\end{array}$ & 0.082 & 0.010 \\
\hline
\end{tabular}

We use the reported total government spending on the public long-term care programs in 2012. MYR 32.59 million, in which MYR 26.79 million were spent on residential care and MYR 5.80 million on nursing home care. Hence, in 2012, the average annual costs per person for residential and nursing home care were MYR 14504 and MYR 24, 472 per person, respectively. The average costs for nursing home care are significantly higher than residential care due to the greater intensity of care needed by those living in nursing home care compared to residential care. Furthermore, most of those living in nursing home care suffer chronic illnesses, requiring extra medical care and assistance in daily living. 
Next, we estimated the QALY based on an elderly's responses to the WHS (2012). There were 796 elderlies, with 429 (54\%) males and 367 (46\%) females. The respondents' age distribution is shown in Figure 1 -most elderlies aged 75 years and below and only a small number of them aged 75 and above. We selected questions that are related to the five dimensions of the EQ5D - mobility (q2010), self-care (q2020), usual activities (q2060), pain or discomfort (q2030) and depression (q2090) and then the five-digit code of an individual's health status were collected. Figure 2 shows the number of elderlies by five dimensions and three levels of health status. Most elderlies reported no problem in mobility, self-care, usual activities, pain and discomfort and depression, and only a few have major problems in all five dimensions.

Using the time-trade-off regression model from Yusof et al. (2012), the fivedigit code was reduced to a single index known as an HRQoL index. The HRQoL index is usually normalised to lie between 0 (death) and 1 (representing total health). Next, we calculated each of the elderly's HRQoL indices and estimated the average value from the two groupings represents the mean score of the EQ-5D, which is the QALY for the groupings, and the results are shown in Table 2.

From Table 2, the estimated QALY of those living in residential care and nursing home care were 0.632 and 0.423 , respectively. The QALY of those living in nursing home care is, reasonably, lower than those in residential care due to their worse chronic health conditions, with the majority being categorised as severely disabled. As a result, the cost-effectiveness of the residential care program is MYR 22,948 per QALY, lower than the costeffectiveness of nursing home care MYR 57,822 per QALY. These results reflect positively on the residential care program

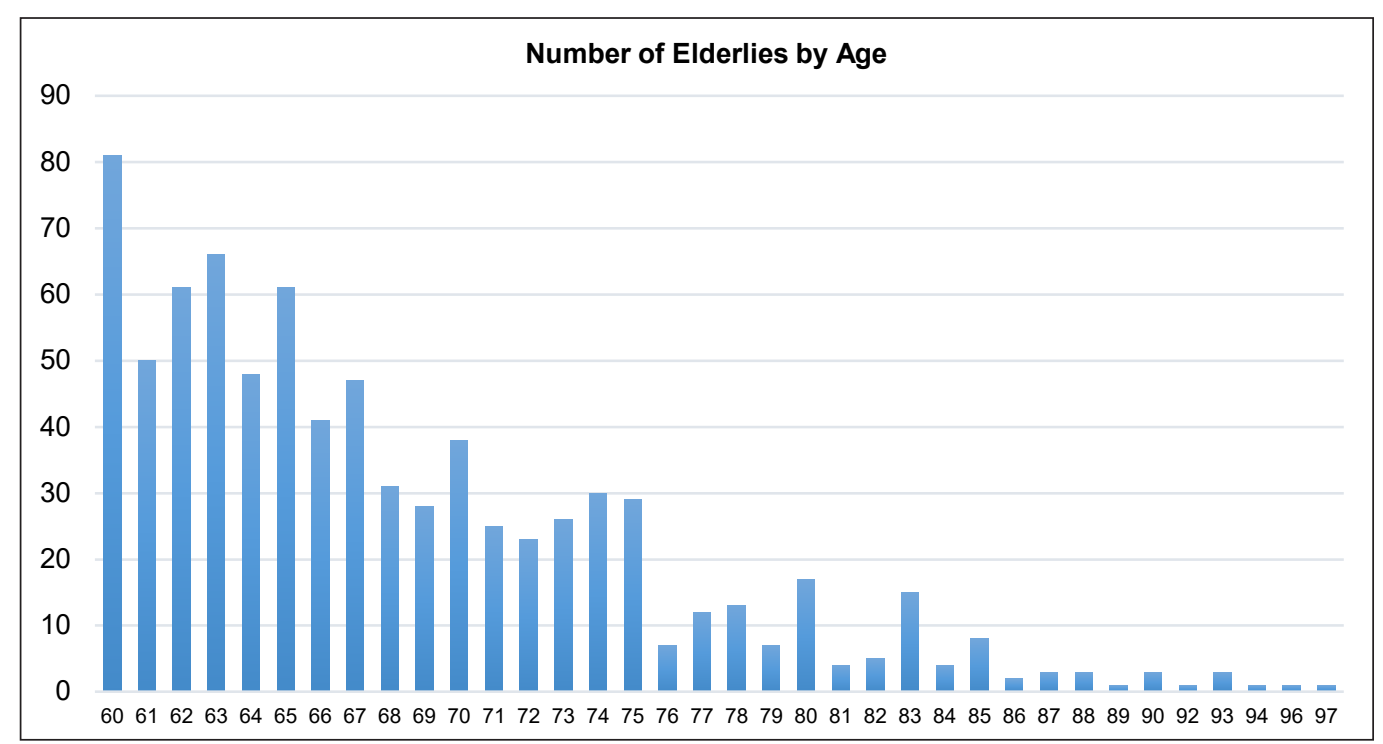

Figure 1. Number of Malaysian elderlies from WHS (2012) by age 


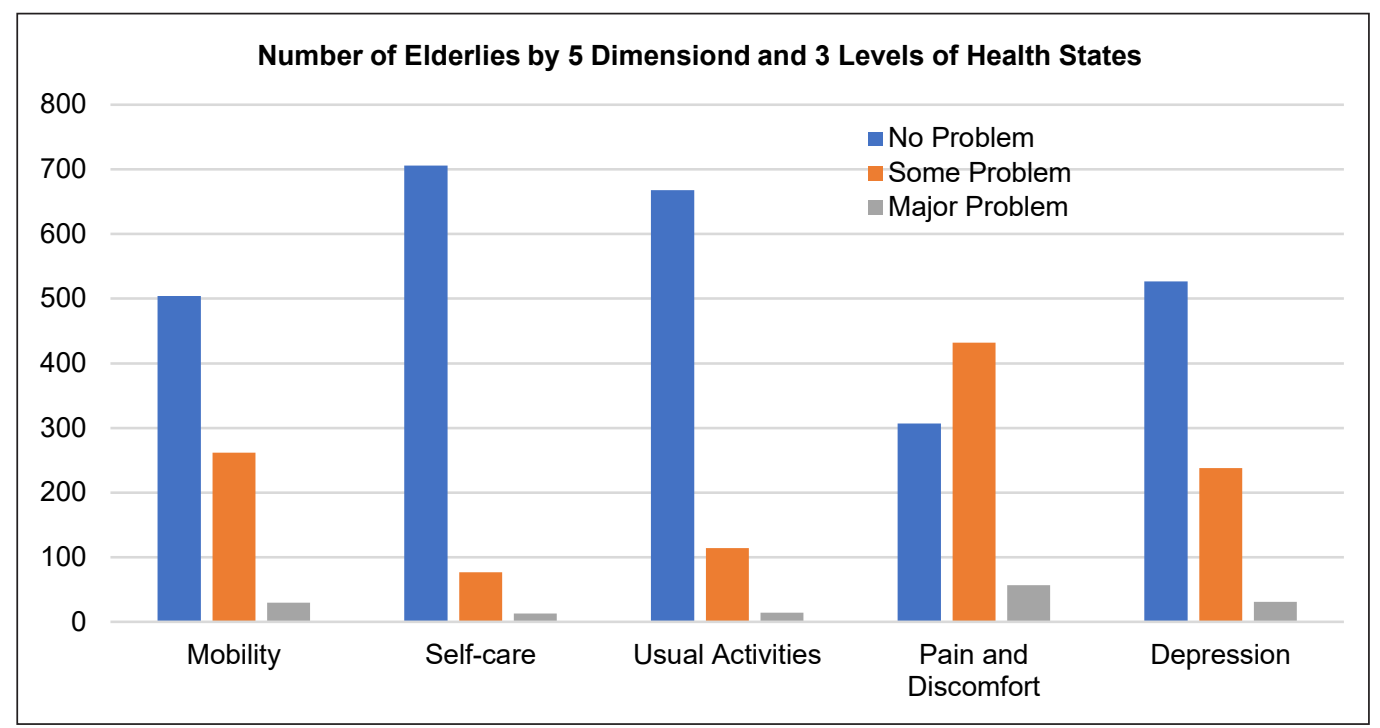

Figure 2. Number of Malaysian elderlies from WHS (2012) according to five dimensions and three levels of health states

Table 2

Quality-adjusted life year of elderlies living in Malaysian public long-term care institutions and the Costutility analysis of both institutions

\begin{tabular}{|c|c|c|}
\hline & Residential care & Nursing home \\
\hline Average costs per person (MYR) & 14,504 & 24,472 \\
\hline QALY & 0.63 & 0.42 \\
\hline Cost/QALY (MYR) & 22,948 & 57,822 \\
\hline WTP/ QALY (MYR) & \multicolumn{2}{|c|}{$(19,929-28,470)$} \\
\hline Effectiveness of the program & Effective & Not Effective \\
\hline
\end{tabular}

as it has the best (lowest) cost-effectiveness ratio compared to nursing home care. It takes MYR 22,948 to generate an additional QALY in the residential care program. For nursing home care, an additional QALY will cost MYR 57,822, which is more than double residential care costs.

For further analysis of these programs' cost-effectiveness, the costs per QALY of each program were compared with Malaysian's willingness to pay (WTP) for a quality-adjusted life-year (QALY). World Health Organization recommended that any intervention in a country would be considered cost-effective if it were below the recommended value of three times the GDP per capita threshold. This threshold value remains arbitrary and may not be entirely relevant because it depends only on the estimation of the regional GDP per capita - a nation's average wealth does not necessarily indicate the state of wealth of every member of society. Few countries have explicitly estimated their WTP threshold. For example, the United Kingdom has a threshold value of between 
GBP 20,000 and GBP 30,000 per QALY gained, whereas Ireland's threshold is Euro 20,000 per QALY gained (Shafie et al., 2014). Thus, research from Shafie et al. (2014) attempted to estimate Malaysia's WTP per QALY threshold and found that any intervention below MYR 29,080 is considered cost-effective. However, this threshold is based on the health status of the Penang population only in which the demographic composition does not entirely represent Malaysia population - Chinese is the majority in Penang, which is inconsistent with the fact that Malay is the majority of the Malaysian population. Lim et al. (2017) estimated the cost-effectiveness threshold of health care intervention programs based on Malaysian population health status description using a Malaysian population survey conducted between December 1, 2012, and December 31, 2014. The study found that the WTP for the Malaysian population is between MYR 19,929 and MYR 28,470.

Compared to the WTP per QALY threshold from Lim et al. (2017), Malaysian residential care is cost-effective, as the cost per QALY value falls within the willingness to pay threshold. On the other hand, results show that nursing home care in Malaysia is ineffective due to the costs per QALY values lying outside the WTP range. One reason for this outcome is that the costs associated with nursing home care are far more expensive than residential care, which are double in Malaysia. The high costs of nursing home care reflect the extensive care and medical attention needed to treat the severely disabled elderly. Hence, residential care is effective, whereas the nursing home program is ineffective for Malaysian long-term care. In this context, further research is needed to develop both rigorous QALY values for Malaysian long-term care programs and the WTP per QALY threshold.

\section{CONCLUSIONS}

Population ageing is a topical issue in Malaysia. The proportion of older people has increased rapidly, resulting in a greater demand for long term care. The sustainability of current long-term care models in the country has been debated by researchers, together with suggestions for change and reform. Nonetheless, none provide quantifiable research about the quality of life of elderlies living in a formal longterm care institution. Therefore, this paper seeks to contribute to this area of research and perform the economic evaluation for public long term care institutions provided by the government. Results suggest that the residential care program is cost-effective, while nursing home care for severely disabled people is ineffective. The findings of this research may contribute to the development of long-term care policy in Malaysia particularly, to plan for the costeffective long term care program for the elderlies.

\section{ACKNOWLEDGEMENT}

The authors gratefully acknowledge research funds received from the Ministry of Education (MOE) and Institute of Research 
Management Centre (RMC), Universiti Teknologi MARA (UiTM) through the Fundamental Research Grant Scheme with the file number of 600 -IRMI/FRGS 5/3 $(125 / 2019)$.

\section{REFERENCES}

Ambigga, K. S., Ramli, A. S., Suthahar, A., Tauhid, N., Clearihan, L., \& Browing, C. (2011). Bridging the gap in ageing: Translating policies into practice in Malaysian primary care. Asia Pacific Family Medicine 10(2), 1-7. https:/doi. org/10.1186/1447-056X-10-2

Bernama. (2012, October 16). Hampir 6,000 warga emas huni rumah orang tua seluruh negara [Nearly 6,000 senior citizens live in aged care homes across the country]. The Borneo Post. https://www.theborneopost.com/2012/10/16/ hampir-6000-warga-emas-huni-rumah-orangtua-seluruh-negara/

Bulamu, N. B., Kaambwa, B., \& Ratcliffe, J. (2015). A systematic review of instruments for measuring outcomes in economic evaluation within aged care. Health and Quality of Life Outcomes, 13, 179-201. https:/doi.org/10.1186/s12955-015$0372-8$

Dahlan, A., Nicole, M., \& Maciver, D. (2010). Elements of life satisfaction amongst elderly people living in institutions in Malaysia: A mixed methodology approach. Hong Kong Journal of Occupational Therapy, 20(2), 71-79. https://doi. org/10.1016/S1569-18611170006-7

Dimana silapnya warga emas [Where is the mistake of senior citizens]. (2012). Hargaemas MY. http:/www.hargaemas.com.my/terkini/dimanasilapnya-warga-emas/

Drummond, M. F., Sculpher, M. J., Torrance, G. W., O’Brien, B. J., \& Stoddart, G. L. (2005). Methods for the economic evaluation of health care programmes. Oxford University Press.
EuroQol. (2019). EQ-5D-5L User Guide 2019. https:// euroqol.org/publications/user-guides.

Forsyth, D. R., \& Chia, Y. C. (2009). How should Malaysia respond to its ageing society? Medical Journal Malaysia, 64(1), 46-50.

Goh, Z. Y., \& Lai, M. M. (2013). The formal and informal long-term caregiving for the elderly: the Malaysian experience. Asian Social Science, 9(4), 174-184. https://doi.org/10.5539/ass. v9n4p174

Kiik, S. M., \& Nuwa, M. S. (2020). Quality of life of the elderly: A comparison between communitydwelling elderly and social welfare institutions. Medisains, 18(1), 9-13. http://doi.org/10.30595/ medisains.v18i1.6940

Kumar, P. B. A., Udyar, S. E., Arun, D., Sai, S. (2016). Quality of life of elderly people in institutional and non-institutional setting: A cross-sectional comparative study. National Journal of Community Medicine, 7(7), 546-550.

Li, P. L., \& Khan, T. H. (2012). Designing long term care accommodation for senior citizens: The need for a design code in Malaysia. British Journal of Arts and Social Sciences, 8(1), 45-56.

Lim, Y. W., Shafie, A. A., Chua, G. N., \& Hassali, M. A. A. (2017). Determination of cost-effectiveness threshold for health care interventions in Malaysia. Value in Health, 20(8), 1131-1138. https://doi.org/10.1016/j.jval.2017.04.002

Mafauzy, M. (2000). The problems and challenges of the ageing population of Malaysia. Malaysian Journal of Medical Sciences, 7(1), 1-3.

Makai, P., Brouwer, W. B., \& Koopmanschap, M. A. (2014). Quality of life instruments for economic evaluations in health and social care for older people: A systematic review. Social Science \& Medicine, 102, 83-93. https://doi.org/10.1016/j. socscimed.2013.11.050

Mohd Tobi, S. U., Fathi, M. S., \& Amaratunga, D. (2017). Ageing in place, an overview 
for the elderly in Malaysia. AIP Conference Proceedings, 1891(1), Article 02010. https://doi. org/10.1063/1.5005434

Nikmat, A. W., Hawthorne, G., \& Al-Mashoor, H. (2011). Quality of life in dementia patients: nursing home versus home care. International Psychogeriatrics, 23(10), 1692-1700. https://doi. org/10.1017/S1041610211001050

Shafie, A. A., Lim, Y. W., Chua, G. N., Azmi, M., \& Hassali, A. (2014). Exploring the willingness to pay for a quality-adjusted life-year in the state of Penang, Malaysia. Clinico Economics and Outcomes Research, 6, 473-481. https://doi. org/10.2147/CEOR.S67375

Shiroiwa, T., Igarashi, A., Fukuda, T., \& Ikeda, S. (2013). WTP for a QALY and health states: More money for severer health states? Cost Effectiveness and Resource Allocation 11, 22-28. https://doi.org/10.1186/1478-7547-11-22

Su, S. W., \& Wang, D. (2019). Health-related quality of life and related factors among elderly persons under different aged care models in Guangzhou, China: A cross-sectional study. Quality of Life Research, 28,1293-1303. https://doi. org/10.1007/s11136-019-02107-x
The EuroQol Group. (1990), EuroQol-A new facility for the measurement of health-related quality of life. Health Policy, 16(3), 199-208. https://doi. org/10.1016/0168-8510(90)90421-9

Vitorino, L. M., Paskulin, L. M. G., \& Vianna, L. A. C. (2013). Quality of life of seniors living in the community and in long term care facilities: A comparative study. Revista Latino-Americana de Enfermagem, 21(Spec), 3-11. https://doi. org/10.1590/S0104-11692013000700002

Warga Emas. (2021, August 12). Jabatan Kebajikan Masyarakat. https://www.jkm.gov.my/jkm/ index.php?r=portal/submenu\&id=UkQ5T2ZC TIVkeWFYU2pJZGM5QIE5UT09

World Health Survey. (2012). World Health Survey, Malaysia. The World Health Survey. World Health Organisation. http://www.who.int/ healthinfo/survey/

Yusof, F., Goh, A., \& Azmi, S. (2012). Estimating an EQ-5D value set for Malaysia using time trade off and visual analogue scale method. Value in Health, 15, 85-90. https://doi.org/10.1016/j. jval.2011.11.024 